\title{
$(6$
}

\section{POLOS CAMIÑOS DA MOTIVACIÓN E DA XEOLINGÜÍSTICA: OS NOMES DA VÍA LÁCTEA ${ }^{1}$}

\section{ON THE ROADS OF THE MOTIVATION AND OF THE GEOLINGUISTICS: THE NAMES OF THE MILKY WAY}

\author{
Rosario Álvarez ${ }^{2}$ \\ Instituto da Lingua Galega - Universidade de Santiago de Compostela
}

\begin{abstract}
Resumo: Estudamos as denominacións da nosa galaxia no dominio lingüístico do galego e do portugués en Portugal e no Brasil, con base principal nos datos do Tesouro do léxico patrimonial galego e portugués (TLPGP). Analizámolas desde o punto de vista da motivación, moi arraigada en crenzas ancestrais con que a humanidade integrou ese fenómeno celeste en diferentes culturas ao longo de todo o mundo; esta perspectiva ten especial importancia no ámbito territorial do bloque lingüístico galego-portugués, ao se estender en áreas transoceánicas e superpoñerse a outras linguas e culturas. Analizámolas tamén desde o punto de vista xeolingüístico, mostrando a relación entre o afastamento do núcleo cultural orixinario, a vixencia ou perda da motivación e a mudanza na forma lingüística adoptada, sen esquecermos as posibilidades de novas motivacións adquiridas por hibridación nesa expansión territorial.
\end{abstract}

Palavras-chave: Variación léxica; Motivación semántica; Xeolingüística; Camiño de Santiago; Vía Láctea.

\footnotetext{
1 Esta contribución inscríbese no marco do proxecto Tesouro do léxico patrimonial galego e portugués, que se desenvolve no Instituto da Lingua Galega da Universidade de Santiago de Compostela, coa participación un amplo equipo (aberto) de investigadores de universidades portuguesas e brasileiras (http://ilg.usc.gal/Tesouro/). Na actualidade conta cunha axuda económica ao abeiro do Convenio Accións I+D (Xunta 2021-2022).

2 rosario.alvarez@usc.gal
} 
Abstract: This article studies the names of our galaxy in the linguistic domain of Galician and Portuguese (spoken in Portugal and Brazil), based mainly on data extracted from the Galician and Portuguese word bank (Tesouro do léxico patrimonial galego e portugués). We analyse the data from the point of view of motivation, deeply rooted in the ancient beliefs with which human beings integrated this phenomenon into different cultures worldwide. This perspective is particularly relevant in the geographical scope of the Galician-Portuguese linguistic continuum, which extends on both sides of the Atlantic Ocean and overlaps with other languages and cultures from very different families. The data is also analysed from a geolinguistic point of view, by showing the relationship between the distance from the original cultural centre, the continuity or loss of motivation, and the changes in the adopted linguistic forms, not overlooking the possibilities of acquisition of new motivations through hybridisation during the territorial expansion.

Keywords: Lexical variation; Semantic motivation; Geolinguistics; The Way of Saint James; The Milky Way.

\section{INTRODUCIÓN}

Os benqueridos colegas da Bahia convócannos arredor dos estudos de lingua e literatura galegas con ocasión dunha dupla conmemoración, o Ano Santo compostelán, que unha vez máis traerá a Santiago de Compostela milleiros de persoas de toda condición chegadas de todas as partes do mundo, e o $25^{\circ}$ aniversario do CELGA/UFBA, que, non o esquezamos, tomou como imaxe un peregrino de capa estrelada camiñante sobre a rosa dos ventos.

A escolla desta miña contribución está determinada por ambas as celebracións, pois toma como obxecto o Camiño de Santiago: non no sentido dese itinerario cultural europeo, con múltiples ramificacións confluentes en Santiago de Compostela (o Santiago de Galicia), polo desde hai tantos séculos transitaron, en camiño de ida e volta, intensamente, os peregrinos e a cultura; senón na súa translación ao ceo nocturno, como denominación da nosa galaxia, ese gran carreiro de prata tamén chamado Vía Láctea. Ten para min, ademais, o aliciente de seguir no carreiro ás queridas Suzana Cardoso e Ana Teles (2017), de saudosa memoria, e Vanderci Aguilera (2019), da parte brasileira, e aos non menos queridos João Saramago e Fernando Brissos (2019), da parte portuguesa.

Vai dedicada a Mailson e Araceli, actuais proeiros do CELGA (beizón!) e aos seus benqueridos antecesores e antecesoras, con emocionada lembranza das colegas e os colegas da UFBA que crearon o Centro de Estudos Galegos no xa afastado ano de 1975 (logo fará medio século!) e o mantiveron en pé, coas sucesivas transformacións, ata a fermosa realidade presente. 
A galaxia é visible desde a superficie terrestre como unha gran banda prateada que cruza o ceo, dun estremo ao outro, nas noites sen nubes e sen a contaminación lumínica das aglomeracións urbanas. Circunda toda a esfera terrestre, orientada de tal xeito que cruza o ceo dos dous hemisferios e pode ser vista desde calquera lugar do mundo.

A visión da galaxia cruzando o firmamento acompañou a humanidade desde os albores e está presente nas culturas ancestrais de todo o mundo. Unhas culturas equiparárona cun gran río, copia das grandes correntes de auga que sucan a superficie da Terra ou de curso propiamente celeste; outras viron nela unha vía de comunicación terrestre -ou o seu transunto no ceo-, que conduce a un lugar ou estado especial; unhas e outras, en definitiva, interpretárona como unha canle vivificante pola que transitan ou se orientan os seres humanos (vivos ou mortos, e non só) cos seus anhelos e a súa cultura. Naturalmente, existen outras explicacións mitolóxicas que escapan a estes dous grandes grupos que cobren de xeito complementario a redondez do globo.

A metáfora, e os mitos explicativos, van máis alá por todo o mundo. A luminosidade no ceo nocturno foi asimilada coa fariña, co semen, coa prata, con pedras preciosas, con brasas e cinza, coa poeira de animais ao galope, coas faíscas levantadas polos seus cascos, con palla estrada, con leite derramado..., tamén cun saco de estrelas deitadas todas xuntas coas présas. Interésanos de xeito particular a imaxe do leite porque, ao ser frecuente nas antigas culturas mediterráneas, está na base da cultura occidental e das súas denominacións máis divulgadas, tanto na voz galaxia coma en vía láctea: a primeira procede do gr. $\gamma \alpha \lambda \alpha \xi$ ća $\alpha$ 'lácteo', adxectivo relacionado con $\gamma \alpha \dot{\alpha} \lambda \alpha,-\alpha \kappa \tau$ ç 'leite'; a segunda contén o adxectivo lat. LACTEUS 'de leite'. Repárese nos equivalentes en diversas linguas occidentais, como al. Milchstraße, fr. voie lactée ou ing. milky way. No mito grego máis común, e máis reproducido na cultura europea do último milenio, formouna o leite derramado por Hera cando, ao se decatar de que está aleitando a Heracles -fillo de Zeus e a mortal Alcmena-, aparta bruscamente o meniño e deixa que o leite divino se proxecte cara ao ceo (GRAVES, 1985, p. 111). Un dos mitos exipcios tamén a identifica co leite, neste caso o que mana dos tetos de Hathor, deusa da fertilidade, convertida en vaca celeste (WILKINSON, 2016, p. 244). 


\section{2 ÁMBITO DE ESTUDO, FONTES E DENOMINACIÓNS}

O noso estudo centrarase nas denominacións no espazo lingüístico do galego, do portugués europeo e do portugués brasileiro, cunha perspectiva xeolingüística e motivacional. Tomamos como base os datos do Tesouro do léxico patrimonial galego e portugués (no sucesivo TLPGP), complementados con outras fontes de carácter xeolingüístico ou lexicográfico.

A amplitude denominativa, con máis de tres ducias de termos diferentessen contar as variantes gráficas nos tres territorios ${ }^{3}-$, redúcese en diversos chanzos de abstración ata chegar a un gran grupo motivacional, unificado pola idea base de 'camiño', que é o que domina na cultura europea. As vinculacións zoomorfas que se rexistran no Brasil, ben avaladas noutros proxectos xeolingüísticos (Mato Grosso do Sul (OLIVEIRA, 2007) e Paraná: rabo de galo, rabo de peixe, ema, avestruz na noite estrelada..., apud AGUILERA, 2019), son debidas á hibridación cultural, grazas á cal a lingua dos europeos se fai eco das crenzas dos poboadores orixinarios 4 . É máis difícil establecer a orixe cultural da motivación con sepultura, sobre a que volveremos máis adiante.

\section{O CAMIÑO}

A práctica totalidade das denominacións recollidas no ámbito galegoportugués son locucións nominais ${ }^{5}$, das que a maior parte conteñen o concepto 'camiño, vía de comunicación terrestre'. Estas son as palabras implicadas, coas respectivas variantes gráficas e morfolóxicas documentadas entre chaves: camiño \{camiño, caminho, camino\}, carreira, carreiro \{carreiro, carreiros\}, carretera, carrilleira, estrada \{estrada, strada, stradinha\}, pasadas, poldras, verea, vía \{vía, via\}.

\footnotetext{
${ }^{3}$ Tampouco temos en conta voces non específicas ou inconcretas que dan os informantes en traballo de campo, do tipo claro, estrelado, nebulosa, constelação, cosmos etc.

${ }^{4}$ Véxase, como mostra, na área limítrofe con Mato Grosso do Sul [MS] en Bolivia, Paraguai e Arxentina: "Se confirmó que Mañic Lta'a es el Dueño de los ñandúes, un ser poderoso descripto como el Ñandú más grande de todos los mañics, el cual es blanco y tiene unas franjas negras en el cuello, vive en el cielo (siempre está) pero muy raras veces se lo ve en el monte. (...) Mientras en el estrato terrenal se presenta como un ñandú blanco, en el cielo está representado por la Vía Láctea" (CHADWICK; BONAN, 2018). No MS dáse un novo grao de hibridación, ao nomealo como avestruz 'ave corredora africana e arábiga', máis coñecida polos europeos e para a que tiñan denominación nas linguas de orixe.

${ }^{5}$ En Galicia e Portugal só rompe a normalidade gal. poldras; no Brasil aínda se recollen outras coma o xenérico e culto galáxia e posibles abreviacións (cinturões).
} 
De todas elas destacan camiño e estrada, que en certo modo actúan como variantes xeolectais complementarias. Camiño, aínda que existe nos tres territorios, é a base dominante en Galicia e no Brasil, con distinto tipo de especificadores, sobre os que volveremos na alínea seguinte (gal. camiño de san Andrés, camiño de san Campio, camiño de Santiago, camín de Santiago, camiño real / PB, caminho de José, caminho de Maria, caminho de Nossa Senhora, caminho de ouro, caminho de são Felipe, caminho de são Jacó, caminho de são Jorge, caminho de são Salomão, caminho de são Tiago, caminho de Tiago, caminho do Calvário, caminho do céu); segundo os nosos datos, non acontece o mesmo en Portugal, onde é infrecuente (caminho de Santiago, camino de Santiago 6 , caminho de Nossa Senhora). No espazo portugués domina estrada, non só pola amplitude denominativa en varias locucións (estrada de Santiago, estrada de são Tiago, estradinha de Santiago, estrada do Santiago, estrada da Galiza, estrada dos almocreves, estrada dos moleiros, estrada do Algarve, estrada de São Vicente, estrada de macadame), senón pola extensión territorial, como se pode comprobar cotexando os mapas 1 e 2, que representan respectivamente a distribución nos dous sintagmas máis significativos, caminho de Santiago e estrada de Santiago, e mais porque nos mesmos lugares en que se recolle a primeira tamén existe a locución con estrada; falta por completo en Galicia e é excepcional no Brasil7. A aplicación a esta distribución areal dun dos principios básicos da estratigrafía lingüística permite concluír con verosimilitude

\footnotetext{
${ }^{6}$ Rexistrada en Constantim (Miranda do Douro), é unha solución mirandesa. O mirandês forma parte do bloque asturleonés e non ten a palatalización característica do bloque galego-portugués nos descendentes de -INU.

${ }^{7}$ Desta diferenza entre PE e PB fanse eco os dicionarios de referencia. Así, no Brasil Houaiss acolle carreira de Santiago, carreiro de são Tiago, estrada de Santiago e caminho de são Tiago como denominacións da Vỉa Láctea; Ferreira inclúe, ademais, a variante estrada de são Tiago; polo contrario, en Portugal Infopédia só indica estrada de Santiago e carreiro de Santiago, e Priberam estrada de Santiago.
} 
que a expansión de estrada a custo de caminho en Portugal veu romper a primitiva unidade, da que queda como testemuño o PB.

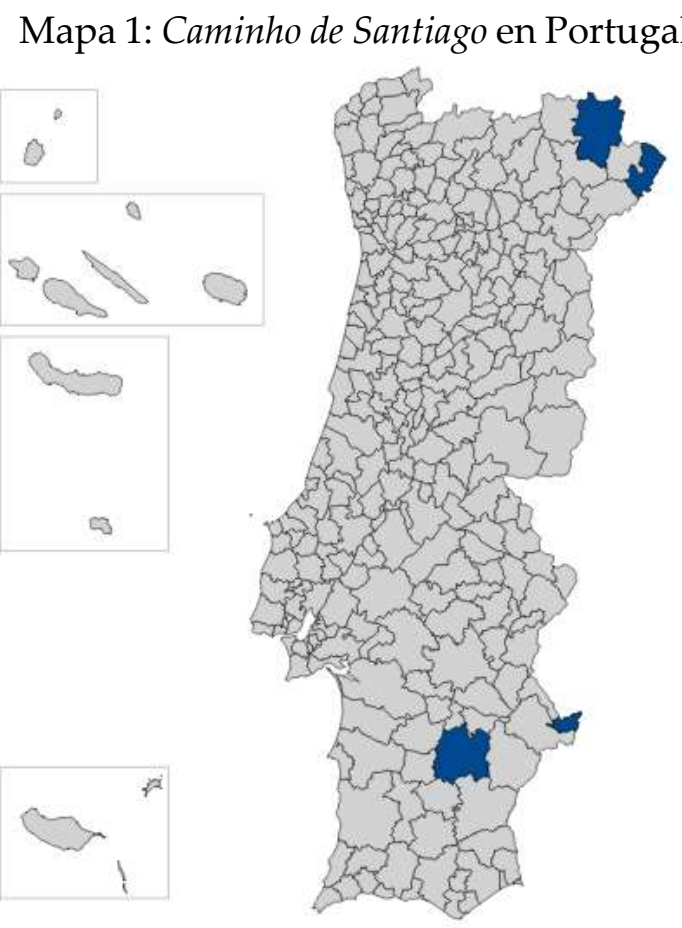

Fonte: TLPGP
Mapa 2: Estrada de Santiago en Portugal

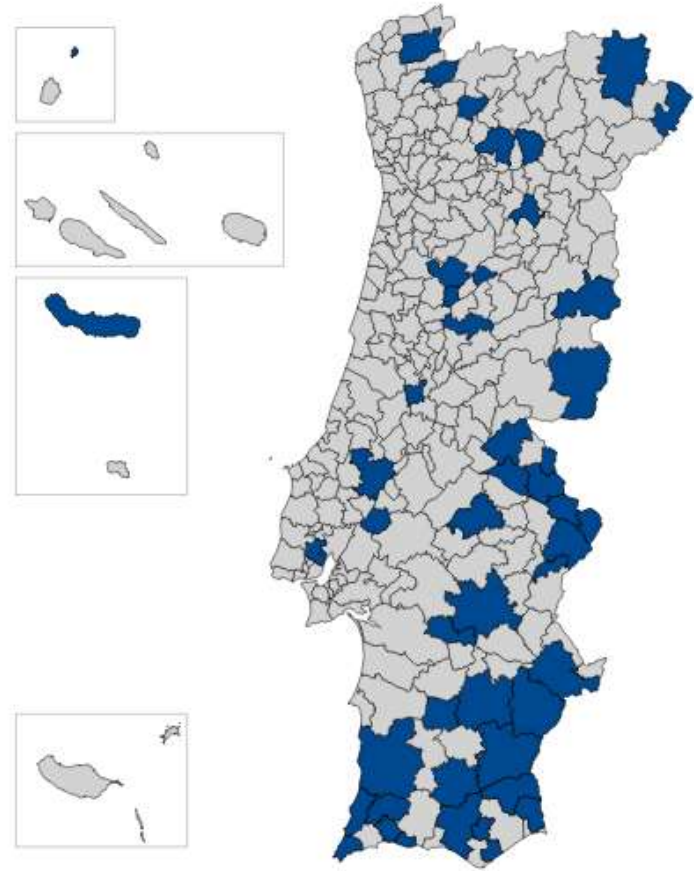

Fonte: TLPGP

A segunda forma en importancia en territorio portugués é carreiro, espallada na metade norte do país e nos dous arquipélagos (carreiro de Santiago, carreiros de Santiago, carreiro do pastor), en realidade no mesmo espazo en que o TLPGP recolle o substantivo carreiro para un tipo de camiño estreito polo que se anda a pé ${ }^{8}$. En Galicia carreiro é frecuente no léxico común, mais o uso en sintagmas que denominen a Vía Láctea é moi esporádico (carreiro das estrelas). A motivación pode ser tanto 'camiño estreito' ${ }^{\prime}$, coma a imaxe das persoas e animais que o poboan transitando de modo continuado por el, como fan as formigas: a primeira é máis acaída para os sintagmas que expresan unha meta ou un usuario; a segunda para os descritivos da súa composición. O uso do plural, ademais das explicacións obvias derivadas do significado do número gramatical, pode tamén apuntar a carreiro co significado de 'rodeira', coma as que labraron os carros

\footnotetext{
${ }^{8}$ Parte dos datos do TLPGP proceden do ALGa (IV: 31) e do ALEPG (Atlas Linguístico-Etnográfico de Portugal e da Galiza, dir. João Saramago). As respostas do segundo para esta cuestión, aínda inéditas, poden visualizarse en Brissos e Saramago (2020, p. 312).

${ }^{9}$ As aproximacións ao significado preciso dentro do campo 'camiño' fanse con criterios actuais, vistos os usos populares documentados no TLPGP e outras fontes. Débese ter isto presente, pois trazos semánticos que hoxe son pertinentes poden ser evolucións moi posteriores ao inicio destas locucións, consonte as mudanzas nos costumes e na tecnoloxía. Tamén mudan no tempo as formas que funcionan como hiperónimos.
} 
século a século incluso no chan de pedra. Compleméntase co substantivo feminino carreira (c. de Santiago, ocasional en Galicia e en Portugal), co que, como acontece en tantos casos, forma un par léxico que denomina dúas entidades semellantes diferenciadas polo tamaño e, consecuentemente, polo feitío. A carreira é un camiño terreo non tan estreito coma o carreiro, pois foi conformándose polo paso continuado dos carros, e non dos peóns; coma este, tamén pode aludir a unha secuencia de persoas, animais ou cousas que se suceden, en ringleiras máis ou menos anchas.

Outras formas de uso esporádico en Galicia implican as palabras verea (vereda de Santiago) e carrilleira (c. de Santiago), ambas 'camiño de terra polo que pasa un carro'; e carretera 'vía interurbana pola que poden circular vehículos de gran tamaño, consonte os usos modernos' (c. de Santiago), equivalente en puntos do S de Galicia ao estrada de Santiago tipicamente portugués. A solución culta vía láctea, coñecida por vía escolar, xorde raramente no traballo de campo nos territorios europeos estudados; a xulgar polos datos do TLPGP (só 1 vez en Galicia) ten maior implantación no Brasil.

A locución pasadas de san Andrés quizais non faga referencia ao camiño mesmo senón ás pegadas que deixan nel os pés dos camiñantes; mais tamén poden ser os pasais que permiten cruzar a pé enxoito a corrente dun regato, en concidencia con poldras.

Nunha pequena área galega NE recóllense locucións con base en carro (carro de Santiago, carrín de Santiago ${ }^{10}$ ). O máis probable é que se trate dunha translación metonímica, visto que na mesma área carro ( carrín) de Santiago denomina a Osa Maior, tamén chamada carro ou carro das estrelas, ou ben a Osa Menor, con ou sen a especificación pequeno (ALGa: IV 27, 28); a mesma confusión dáse en lugares da veciña lingua asturiana e noutros máis distantes (por exemplo, en catalán, carro de Sant Jaume, c. de Sant Joan ou c. de Santiago, ALDC: III 204-205). Con todo, non debemos esquecer que noutras latitudes peninsulares se recolle a lenda de que Santiago percorría o ceo nun carro que levantaba grandes poeiras, unha actividade da que quedan "testemuños" tanto terrestres (vestixios de longas rodeiras) coma celestes (a Vía Láctea) ${ }^{11}$.

\footnotetext{
${ }^{10}$ No NE do territorio galegófono, -INU > -ín, tanto en terminacións como CAMINU > camín coma no morfo do diminutivo, carro $\rightarrow$ carrín.

11 Vallan como mostra os referidos desde Cónchar (Granada): https://www.conchar.com/contenido/m_fotos/csantiago/santiago.htm. A poeira tamén podía ser levantada polo seu espléndido cabalo branco, segundo crenza difundida nas illas Baleares e puntos do Levante español (ALDC: III 204).
} 
Non coñecemos testemuños galegos ou portugueses correspondentes das locucións brasileiras con base en cova, sepultura e forma (c. de Adão e Eva, c. de Salomão; s. de Adão e Eva, f. de Adão e Eva), similares a outros rexistrados, sobre todo, ao $\mathrm{S}$ dunha liña que vai de Mato Grosso do Sul a São Paulo (cf., ademais dalgúns dos citados, covas de Adão, túmulo de Adão e Eva, corpo de Nossa Senhora e caixão de Adão e Eva [ALMS, ALPR], apud AGUILERA, 2019, p. 77-78; cova de Adão, cova de anjo no ALERS: 853). Semellan ter relación coa crenza na vida de ultratumba e no destino común de toda a humanidade, desde as súas orixes. En moitas culturas de todo o mundo a Vía Láctea é a conexión entre o mundo terrenal e o celestial, onde habitan os deuses, e asóciase coa migración das ánimas cara ao Paraíso, en calquera das súas formulacións. Vémolo en diversos testemuños europeos, coma a mitoloxía vikinga no estremo norte ou a mediterránea no sur $^{12}$, e entre eles é pertinente destacar a convicción dos que, facendo o camiño de peregrinación cara ao Finis Terrae, vían no ceo as súas propias almas ou as dos seus antepasados que non puideran percorrelo en vida ${ }^{13}$. Esta crenza estaba ben arraigada en Portugal, e de aí puido pasar ao Brasil:

Todos tinham, pois, de peregrinar em vida a Compostela. Aos que o não tenham podido fazer dava-se-lhes, porém, a possibilidade "de ir lá depois da morte". (...): «-É verdade que vão as almas en Romaria a Santiago? I -Hui! muito certo, as que lá não foram em vida!» [Sá de Miranda, 1560] (CUNHA, 2013, p. 125).

Mais, consonte a grande extensión da crenza, de raíces antigas en todo o globo, esta puido tomarse con igual probabilidade da cultura nativa americana, pois que "Pour la plupart des Amérindiens, la Voie lactée este une allée céleste que peuvent emprunter les âmes des morts" (WILKINSON, 2016, p. 289).

\footnotetext{
${ }^{12}$ En Ibiza, o camí carrer de Sant Jaume recibe o nome de camí de ses Ànimes ('camiño das ánimas'); tamén dentro do dominio catalanófono, na costa valenciana, recóllese camí al/del cel (ALDC: III 204) en referencia ao que deben percorrer as ánimas dos defuntos.

${ }^{13}$ A obriga de peregrinar que non remata coa morte está moi arraigada na nosa cultura, como veremos a propósito do culto a Santo André. Na tradición popular portuguesa, a xulgar pola cántiga, esta atracción de vivos e mortos foille atribuída a Santiago: «São Tiago de Galiza / É um cavaleiro forte, / Quem ali não for em vida, / Há-de ir lá depois da morte» (recollida por Leite de Vasconcellos na vila trasmontana de Carrazeda de Ansiães; apud CUNHA, 2013, p. 122, onde se mencionan outros testemuños de interese).
} 


\section{CAMIÑO DE ONDE, DE QUEN, DE QUE?}

Ao analizarmos o segundo membro da locución, observamos que pode orientar cara a un lugar, con nome propio (topónimo: país, localidade, santuario...) ou común; pode indicar a relación especial desa vía cun persoeiro, santo ou non, chamado polo seu nome, ou cun grupo humano; pode, finalmente, apuntar a unha característica física distintiva.

\subsection{O destino}

O destino preferente é Santiago de Compostela, localidade de Galicia que debe o seu nome a que, desde as primeiras décadas do século IX, naquel lugar afastado de occidente se rende culto a Santiago o Maior, tamén chamado Xacobe, fillo do Zebedeo e de María Salomé, un dos doce apóstolos de Xesús e nomeado en Galicia como O Apóstolo, por antonomasia. Segundo a tradición xacobea, o ermitán Paio e outros fieis, grazas a certas experiencias visionarias sobrenaturais, descubriron nun outeiriño próximo a un antigo castro, xa abandonado, un enterramento cunha tumba marmórea. Advertido o bispo Teodomiro (m. 847), axiña o identificou como a sepultura oculta do apóstolo Santiago, que morrera mártir por decapitación en Xerusalén no ano 44 e que os seus discípulos embarcaran secretamente para enterralo en Hispania, nos confíns do mundo coñecido; posto en coñecemento do rei Afonso II (760-842), determinouse construír naquel lugar un santuario (igrexa, baptisterio e cenobio) e trasladar para alí a sede episcopal de Iria. A partir dese momento, nunha península dividida entre os reinos cristiáns ao norte e os territorios ocupados pola expansión do islam ao sur, comeza a promoción deste lugar como destino de peregrinación, ata os nosos días.

No Codex Calixtinus (séc. XII) ${ }^{14}$ recóllese a lenda segundo a cal o propio apóstolo Santiago se lle apareceu ao emperador Carlomagno (ca 745-814)

${ }^{14} \mathrm{O}$ Codex Calixtinus é o manuscrito máis antigo (s. XII), conservado na catedral de Santiago de Compostela, do Liber Sancti Jacobi. Este tivo unha gran difusión na Europa medieval, como testemuñan as numerosas copias máis ou menos completas e fieis conservadas en diversos países; de todas as súas partes, a máis divulgada nesa altura foi precisamente a do Turpín, a dedicada a Carlomagno e as súas xestas. Desde mediados de séc. XIX sucedéronse as traducións deste monumento da cultura compartida, por veces parciais, ás máis diversas linguas europeas. $\mathrm{O}$ Codex foi verquido ao galego, en forma extensa pero non completa, xa en época medieval, nos Miragres de Santiago, que conservamos nun texto de fins do séc. XIV, ou comezos do XV, que 
incitándoo a tomar de novo o mando dos seus exércitos, entrar na península ibérica e liberar Galicia, onde está o seu sepulcro, e todo o camiño que conduce ata el. Ocorre isto cando Carlos está cavilando en que pode ser esa banda luminosa que cruza o ceo, dun a outro confín, descrita así nos Miragres de Santiago ${ }^{15}$ :

hũu camjno d'estrelas que se começaua sóbrelo mar de Frisa et ýa per ontre Alamana et Ytalia et per ontre França et Aquita[n]ia et ýa dereytamente per meogo da Gascona et per Nauara // (fol. 18r) et per Espana, et ýa ferir en Galiza en aquel lugar onde o corpo de Santiago jazía ascondudo.

Isto acontece despois de que Carlos, que xa "conquereu con gran traballo moytas partes do mundo; convén a saber: Ingraterra, França, Alamana, Leorena, Bretana, Bergona, Jtalia et tódalas outras terras et çidades de mar a mar", decide retirarse a descansar. Aparéceselle entón Santiago, vestido de cabaleiro, "tan fremoso que non podería máis", para recriminarlle que non completase a conquista e comunicarlle que tamén debe liberar dos mouros a "súa" terra e o "seu" camiño, isto é, o camiño terrestre que conduce a Galicia, o lugar en que el xace soterrado desde que os seus discípulos trouxeran ocultamente o seu corpo desde Palestina. Exponlle que foi Deus mesmo quen o escolleu para esta misión especial e que debe seguir ese camiño que se lle mostra no ceo, e ofrécelle a súa axuda sobrenatural. Para captar a súa vontade, o Apóstolo profetiza a importancia que adquirirá este camiño de peregrinación por todos os séculos dos séculos e, en premio pola súa intervención, promete a Carlos a gloria eterna e a louvanza de todas as xeracións, ata a fin do mundo. Repárese en que non o incita a desvelar o lugar en que xace escondido o seu corpo, senón a liberar o camiño terrestre e iniciar a peregrinación, e facer isto seguindo o carreiro marcado no ceo ata o lugar exacto. A novidade reside na precisión da meta, posto que a existencia dun carreiro que percorre o ceo de leste a oeste, no mesmo sentido có percurso da expansión da humanidade polo continente, está presente desde tempos moitos máis recuados nas diversas mitoloxías europeas.

semella copia dun orixinal anterior descoñecido. Existen outras versións modernas parciais, mais cómpre destacar a espléndida tradución íntegra, Códice Calixtino, publicada en 2009.

${ }^{15}$ Citamos pola edición máis recente, tamén a de maior rigor filolóxico (LORENZO, 2004). 
Et marauĩllome moyto, tu, que tantas terras et tantas vilas liuraste do poder dos mouros, por que non liuraste a mjna; porque che faço a saber que, así como te Deus fezo máis poderoso ca tódolos outros rrex da terra, que así te escolle para liurares a $\mathrm{m}$ [iñ]a terra et o meu camjno do poder dos mouros, et para darche por ende coroa de gloria perduráuele. Et o camjno que tu viste enno çeo das estrelas, sabe que che demostra que te deues a yr con moy gran poder et liurar o meu camjno et a $\mathrm{m}$ [iñ]a terra et a visitar et entrar aquel lugar que he en Galiza onde jaz o meu corpo. Et despois que esto for feito, de tódalas terras de cristãos que ha de mar a mar yrán aló en rromaría et averán y de Deus perdom de seus peccados et daranlle y loores porlas boas cousas et maraujllas que fez et faz. Et esto se fará y senpre deslo tenpo da túa vida ata a fim do mundo. Et agora vayte o máys // (fol. 18v) çedo que poderes et eu ajudarte ey en tódalas cousas; et porlo trabalo que y leuares gaanarche ey de Nostro Señor a gloria do Paraýso et o teu nome seerá sempre loado.

É preciso deterse un momento nesta referencia pola súa transcendencia cultural, posto que vincula a importancia do camiño de peregrinación a Santiago e a Galicia con poderosísimos axentes políticos e culturais da maior transcendencia europea. Dun lado o papado, pois quen figura como autor e promotor do Codex é o propio papa Calixto II (ca 1050-1124), gran benfeitor do santuario compostelán e impulsor da peregrinación á Xerusalén de Occidente. Do outro, a intervención de Carlomagno, pois representa non só a suposta unidade política baixo o seu poder senón, sobre todo, o que se deu en chamar o "renacemento carolinxio", un programa de unificación cultural europeo que, baixo o principio do cristianismo romano, conta coa anuencia e implicación da Igrexa. Volvendo ao noso obxectivo presente, non estraña que o destino a Santiago de Compostela da Vía Láctea tomase a relevancia cultural e a difusión europea que perduran ata hoxe.

Se nos atemos aos datos lingüísticos, estes mostran como o afastamento do núcleo cultural orixinario debilita e chega a romper o vínculo motivacional. Mentres en Galicia e no Portugal continental se mantén a noción de se tratar dun haxiotopónimo ben localizado (Santiago) -compatible con estrada da Galiza-, xa nos Açores vemos indicios de que se tende a identificar co santo (un haxiónimo, en definitiva un tipo de antropónimo), como acontece de modo xeral no Brasil ${ }^{16}$. Complementan esta percepción as frecuentes deturpacións do topónimo tanto en Açores (carreiro de Santiagro) coma no S de Portugal (estrada de \{Santiágua,

\footnotetext{
${ }_{16}$ En todos os puntos do $A L E P G$ que conteñen esta forma a pronuncia é [sett]-, salvo na illa de

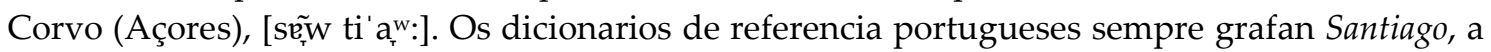
diferenza dos brasileiros, que dan preferenza a São Tiago.
} 
Santiáugua, Santiauga, Santiaua\}), a última tamén rexistrada no Brasil fóra do noso corpus (por caso na Bahia ${ }^{17}$ : caminho de santiágua, c. de santiaua, c. de santáguas; CARDOSO; TELES, 2017, p. 35) e que as autoras relacionan cun cambio total de motivación.

As Figuras 2 e 3 mostram a distribuição da lexia caminho de Santiago e de suas variantes fonéticas que se configuram como casos de perda da motivação principal, a própria relação com o santo da Igreja Católica, São Tiago/Santiago, e o surgimento de uma nova relação motivadora, no caso, com a água ${ }^{18}$.

O segundo destino en orde de importancia tamén ten que ver coa peregrinación, neste caso a Santo André de Teixido (popularmente San Andrés de T.), no estremo N de Galicia, tamén coñecido con San Andresiño de Lonxe. É a todas luces a cristianización dun fenómeno de peregrinación moito máis antigo. O santuario, dedicado a outro dos apóstolos, sitúase nun lugar remoto -“no cabo do mundo", dise con frecuencia en cántigas e refráns-, sobre uns cantís que están entre os máis altos de Europa, ollando o mar; unha atalaia desde a que se podía ver poñer o sol despois océano, dirixíndose á súa morada nocturna na mítica illa de Ávalon, que para os antigos habitantes destes Finis Terrae atlánticos acollía as almas dos benaventurados. Segundo a lenda, ao se queixar santo André de que Santiago, moito máis céntrico, atraía cara a si todos os peregrinos e ninguén se quería achegar a visitar o seu santuario, tan afastado, Deus prometeulle que non había ser menos, porque ninguén podería entrar no seu reino se antes non ía visitalo: "Queda aquí Santo André / que de vivos ou de mortos, / todos te virán a ver". De aí que se impuxese a máxima, século tras século, ata hoxe, dunha

\footnotetext{
${ }^{17}$ Non de modo exclusivo. Formas semellantes foron atestadas noutros estados, como caminhu di santiágua (MS), apud Aguilera (2019, p. 77); caminho de Santiágua, c. de Santi Água, c. de São Tiágua, estrada de São Tiágua ou simplemente Santiágua, nos estados do Sul (ALERS: 853).

${ }^{18}$ Advírtase que, desde a óptica brasileira, as autoras xa se sitúan despois do primeiro cambio motivacional: da meta dun camiño, onde se encontra a catedral erixida como santuario, á figura do santo. A vinculación coa auga forma parte da cosmovisión de culturas sudamericanas; así, para os incas, o deus das tormentas, Illapu, que creou a galaxia ao atraversar o ceo a grandes alancadas, era o dispensador da chuvia desde a Vía Láctea, río celestial correlato do que no nivel terrenal era fonte de toda a auga (WILKINSON, 2016, p. 318). Ora ben, as solucións baianas e as documentadas no $S$ de Portugal teñen que estar conectadas na súa orixe, e non demos encontrado apoio motivacional semellante nesta área cultural; ao $S$ do val do Texo semellan testemuñar un cambio fonético por analoxía con cadeas semellantes (santiguar, água), favorecida pola perda da motivación orixinal. Un cambio inmotivado na forma fonética atopa sentido motivacional na outra beira do mar.
} 
obriga: "A Santo André de Teixido vai de morto o que non foi de vivo", di o saber popular e repetimos todos os galegos conxurando o esquecemento (cf. PENA, 2006).

Da importancia deste camiño de peregrinación na cultura galega dá conta a amplitude da área de dispersión das ocorrencias das denominacións da Vía Láctea que toman este santuario como destino. O mapa 3 mostra como os rexistros de camiño de San Andrés e pasadas de San Andrés se espallan por todo o NE de Galicia, incluída a comarca de Santiago de Compostela; no mapa localizamos os tres santuarios galegos implicados nesta exposición, todos tres no eixe atlántico: no estremo N, Santo André de Teixido (A); no centro, Santiago de Compostela (S); no estremo S, San Campio (C).

Mapa 3: Denominacións da Vía Láctea con Santo André de Teixido como destino

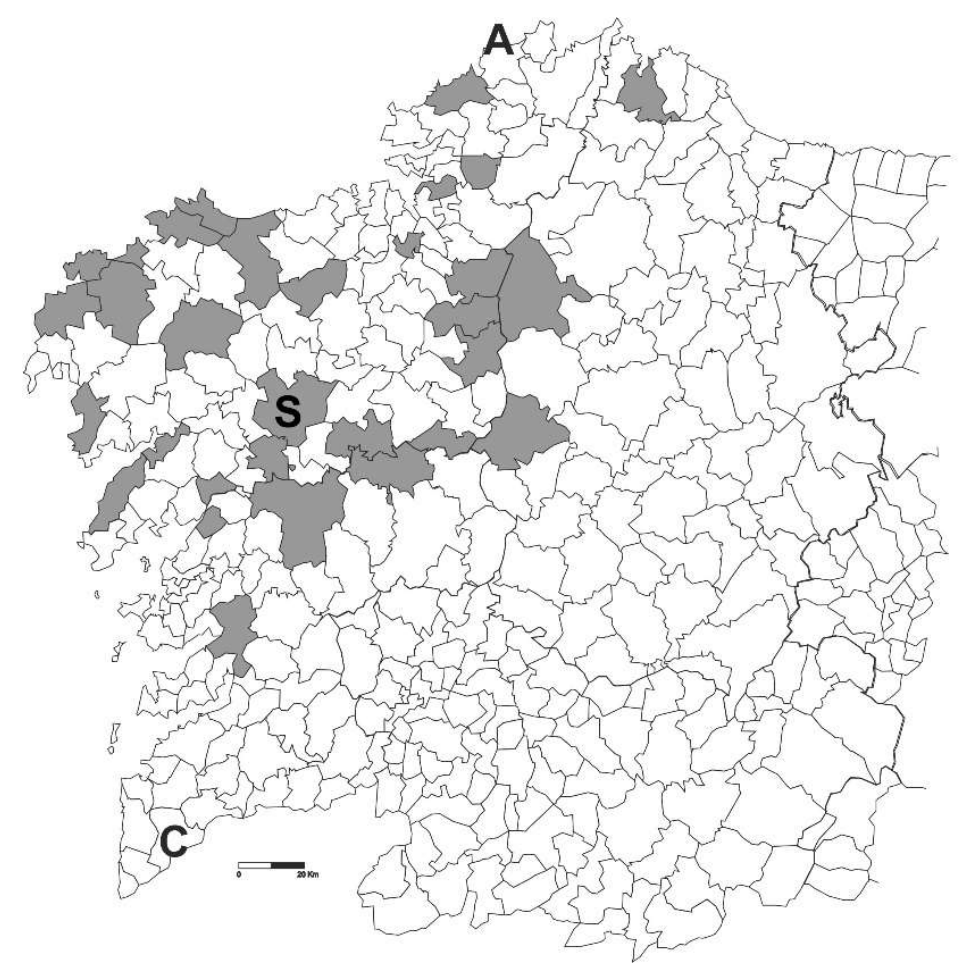

Fonte: TLPGP

O terceiro santuario implicado é o de San Campio, tamén chamado San Campio de Lonxe ou do Monte, inicialmente nunha paraxe remota, nun alto, nas proximidades do río Miño, que fai fronteira con Portugal. San Campio foi un soldado romano que padeceu martirio nos primeiros anos do séc. IV. É moi avogoso para moitas doenzas físicas e psíquicas, pero seguramente favoreceu a 
peregrinación un feito diferencial: encomendábanse a el os mozos que partían para facer o servizo militar ou á guerra. O culto en Galicia é antigo, probablemente dende os alvores da cristianización. É un lugar de peregrinación desde o $\mathrm{N}$ de Portugal e desde puntos moi distantes de Galicia. De feito, as denominacións da Vía Láctea que inclúen este destino localízanse no $\mathrm{N}$ de Galicia, nun itinerario que no mellor dos casos implicaba camiñar varias xornadas e por iso máis necesitado de guía.

No Brasil recóllese estrada de Roma, unha denominación existente noutros lugares e linguas de Europa, testemuño tamén da peregrinación da cristiandade cara á Cidade Santa e probablemente debido á achega doutros grupos de inmigrantes á lingua e cultura brasileiras.

Entre os destinos cómpre considerar, ademais, as lexías estrada da Galiza, estrada do Algarve e, probablemente, estrada de São Vicente, en Portugal; caminho do céu e, quizais, caminho do Calvário, no Brasil.

\subsection{Os camiñantes}

O segundo membro da locución pode aludir ao axente, singular ou colectivo, que se bota ao camiño e se guía polo carreiro celeste. É o que ocorre con estrada dos almocreves, estrada dos moleiros e carreiro do pastor, en Portugal, todos tres oficios que obrigan a habituais desprazamentos nocturnos.

Destaca caminho de Nossa Senhora, esporádico en Portugal e no Brasil, que probablemente faga alusión á crenza católica e ortodoxa da súa asunción, segundo a cal non morreu e foi soterrada senón que subiu ao ceo en corpo e alma. Estrada de Adão garda relación con cova de Adão e Eva e formas semellantes (§ 3), coa migración das almas cara ao lugar onde se reúnen os defuntos seguindo os pasos dos primeiros pais.

Pero na maior parte dos casos son santos católicos, aos que se unen as figuran bíblicas do rei Salomón e de Xacob. Son todas denominacións brasileiras, roto por completo o vínculo coa motivación orixinaria. No noso corpus son estrada de são Felipe, caminho de são Jacó, c. de são Salomão, c. de são Jorge, c. de são Felipe; mais noutras fontes brasileiras recóllense tamén são Pedro, são José, santa Polônia, são Francisco, são João... Non hai elementos que xustifiquen en cada caso a escolla dos nomes destes ou outros santos; a situación xeral nas diversas rexións debe ser similar á descrita para o estado da Bahia: 
Os nomes dos santos evocados nas denominações desses três pontos, até onde se pode apurar, não reflectem nenhuma ligação direta com situação específica dessas localidades, como, por exemplo, denominação de santo padroeiro, nome da freguesia, festa típica da localidade ${ }^{19}$. (CARDOSO; TELES, 2017, p. 38).

A motivación resúmense en que a base denominativa é 'camiño dun santo' e, non lembrando o seu nome concreto, asóciano con outro verosímil. Aguilera (2019, p. 84) dá varias pasaxes significativas, tiradas das gravacións da enquisa de campo. Valla esta como mostra:

INF.- Ah tem un nome aquilo lá, estrada de São Sebastião parece que é. Como tinha o nome daquele negócio lá...

INQ.- Estrada...

INF.- Eu sei que tem um nome é dum santo. Tsc. Ah eu já ando tão esquecida. INQ.-Vamos ver depois, quem sabe a senhora lembra.

(...)

INQ.- É... mas às vezes essas são mais asim... é como se a gente olhasse assim e visse um caminho assim no céu né... como se fosse uma trilha de estrelas tudo.

INF.- Estrada de santiago que nóis chama...

INQ.- Estrada.

INF.- Caminho de santiago.

INQ.- Caminho...

INQ.- É aquele... que nóis chama.

INQ.- A senhora tiña falado qualquer coisa de São Sebastão.

INF.- Não... não era São Sebastião... caminho de santiago... aquele lá.

O paso sucesivo, sempre no Brasil, é desvinculalo do santoral, mediante a supresión do elemento significativo: caminho de Tiago, c. de José. No caso de caminho de Maria, tamén se pode dar por suposto que a interpretación será ‘a virxe María' sen necesidade de explicitalo ${ }^{20}$.

19 Resta explorar a posibilidade de que houbese un santuario distante ao que se fose en peregrinación, mais non semella probable. Os informantes non fornecen comentarios interpretativos neste sentido.

${ }^{20}$ Deixamos á parte solucións como São Tiago ou Santa Maria, ambas do Brasil, por carecermos de elementos dabondo para discernir se se trata dun grao máis na evolución da denominación, con supresión do elemento 'caminho' da base, ou dunha anotación fragmentaria no proceso de enquisa. 


\subsection{O feitío}

Por último, con menor frecuencia, o segundo membro da locución pode aludir a características distintivas do camiño. É o caso do carreiro das estrelas en Galicia, da estrada de macadame en Portugal e do caminho de ouro no Brasil, con tres imaxes diferenciadas.

\section{CONCLUSIÓN}

A motivación revélase unha vez máis como o vínculo fundamental entre a historia lingüística e a historia cultural que nos permite, indo dunha a outra, en direccións alternantes, ampliar o noso coñecemento de ambas.

No estudo das variantes léxicas para denominar a Vía Láctea nos dominios lingüísticos do galego e do portugués (PE e PB) observamos que a motivación principal é a dun 'camiño', e a ela corresponde a maior parte das formas documentadas. É esta a motivación dominante na cultura europea, e por iso non sorprende que sexa a única de Galicia e Portugal; mais non se pode afirmar que a dominancia no Brasil se deba exclusivamente ao traslado da lingua e cultura dos portugueses e outros europeos, pois esta motivación é recorrente en moitas culturas do mundo. Si, en cambio, son atribuíbles á hibridación coa cosmovisión dos poboadores autóctonos as variantes léxicas motivadas por imaxes de animais ou pola auga; tamén son exclusivas do Brasil as que se vinculan con 'sepultura'.

Desde o punto de vista motivacional é importante sinalar que en Galicia se poñen de relevo tres camiños de peregrinación ancestral: por suposto, o de Santiago, hoxe capital de Galicia, que atrae desde hai séculos camiñantes de todas as partes do mundo; mais tamén son importantes, nun ámbito máis próximo, o de San Campio e, sobre todo, o de San Andrés. En Portugal, en cambio, as denominacións que escapan ao destino compostelán aluden a un tránsito utilitario, ben mencionando a dirección con topónimos rexionais ben indicando os usuarios habituais.

A ollada xeolingüística móstrase tamén relevante. A distribución espacial das variantes permite constatar que Galicia e Brasil prefiren realizar este significado mediante a forma léxica camiño caminho, en tanto que Portugal opta por estrada; descartada unha influencia directa masiva do galego sobre o PB, é preciso concluír que foron os falares portugueses os que romperon a unidade 
primitiva, co ascenso de estrada á condición hiperónimo ata o punto de substituír de modo xeral a base das antigas denominacións da Vía Láctea.

Mostra tamén como o afastamento do núcleo cultural orixinario pode romper o vínculo coa motivación e iso ten consecuencias lingüísticas. Así ocorre, por exemplo, coas solucións adoptadas para de Santiago na segunda parte da locución nominal: do haxiotopónimo (Santiago [de Compostela]) ao haxiónimo (São Tiago), e deste ao antropónimo (Tiago); ou ben, a partir do segundo paso, a inclusión de calquera outro nome de santo ou personaxe bíblico seguida da doutros nomes de varón. Esa ruptura cultural con perda da motivación orixinaria pode ser fonte de remotivacións: así, procesos analóxicos que alteran a forma fonética en dialectos portugueses, como ocorreu en Santiágua, cobran sentido e se espallan no Brasil ao se vincularen con mitos que relacionan a Vía Láctea coa chuvia e os trebóns.

\section{REFERENCIAS}

AGUILERA, Vanderci de Andrade. A Via Láctea continua no espaço sideral, mas desaparece dos atlas linguísticos. Guavira Letras, n. 31, p. 74-87. 2019. Dispoñible en: [http://websensors.net.br/seer/index.php/guavira/article/view/865]. Accedido o: 28 feb. 2021.

ALDC = VENY, Joan; PONS I GRIERA, Lídia. Atlas Lingüístic del Domini Català. Volum III. Barcelona: Institut d'Estudis Catalans, 2006.

ALERS $=\mathrm{KOCH}$, Walter; KLASSMANN, Mário Silfredo; ALTENHOFEN, Cléo. Atlas Lingüístico-etnográfico da Região Sul do Brasil. Porto Alegre/Florianópolis/Curitiba: UFRGS/UFSC/UFPR, 2002.

$A L G a=$ GARCÍA, Constantino; SANTAMARINA, Antón (dirs.). Atlas Lingüístico Galego . Vol. IV: Léxico. Tempo atmosférico e cronolóxico [Coordinado por Francisco Fernández Rei]. A Coruña: Instituto da Lingua Galega/Fundación Barrié, 2003.

ALMS = OLIVEIRA, Dercir Pedro (dir.). Atlas Linguístico de Mato Grosso do Sul. Campo Grande: UFMS, 2007.

ALPR = AGUILERA, Vanderci de Andrade. Atlas Lingüístico do Paraná. Curitiba: Imprensa Oficial do Estado, 1994.

BRISSOS, Fernando; SARAMAGO, João. "O Tesouro do léxico patrimonial galego e português como complemento de informação aos atlas linguísticos", LaborHistórico, n. 5 (Especial, 2), p. 290-321. 2019. Dispoñible en: [https://doi.org/10.24206/lh.v5iEspecial2.27056]. Accedido o: 28 feb. 2021.

CARDOSO, Suzana Alice Marcelino; TELES, Ana Regina Torres Ferreira. Outros Caminhos de Santiago... os da Bahia (Brasil). In: ÁLVAREZ DE LA GRANJA, María; BOULLÓN AGRELO, Ana; GONZÁLEZ SEOANE, Ernesto (eds.). Aproximacións á variación lexical no dominio galego-portugués. Revista Galega de Filoloxía. Monografía, 11. 
A Coruña: UdC, 2017. p. 29-42. Dispoñible en: [https://illa.udc.gal/rgf/pdf/mon_11.pdf]. Accedido o: 28 feb. 2021.

CHADWICK, Caroline; BONAN, Leonor. Vínculos entre las representaciones científicas y vernáculas sobre la Vía Váctea en el Gran Chaco. 2018. Dispoñible en: [https://www.researchgate.net/publication/342393785]. Accedido o: 28 feb. 2021.

Códice Calixtino. O Codex Calixtinus en galego. Tradución de Xosé López Díaz / Ilustracións Francisco Leiro. [Santiago de Compostela]: Xunta de Galicia, 2009.

CUNHA, Arlindo de Magalhães Ribeiro da. A devoção e a peregrinação jacobeias em Portugal. Ad Limina, n. 2, p. 85-114. 2011.

CUNHA, Arlindo de Magalhães Ribeiro da. A devoção e a peregrinação jacobeias em Portugal (II). Ad Limina, n. 4, p. 117-152. 2013.

FERREIRA, Aurélio Buarque de Holanda. Novo Dicionário Aurélio da Língua Portuguesa. $3^{\underline{a}}$ ed. revista e atualizada. Curitiba: Positivo, 2004.

GRAVES, Robert. Los mitos griegos. Vol. 1. Madrid: Alianza Editorial, 1985.

HOUAISS, Antônio; VILLAR, Mauro de Salles. Dicionário eletrônico Houaiss da língua portuguesa. Versão 1.0. Rio de Janeiro: Objetiva, 2001.

LORENZO, Ramón (ed. lit.). Miragres de Santiago = Milagres de Santiago = Milagros de Santiago. [Valencia]: Scriptorium Ediciones Limitadas, 2004.

PENA GRAÑA, Andrés. Santo André de Teixido. O Camiño Máxico dos Celtas. Narón: Equona Deseño Editorial, 2006.

TLPGP = Álvarez, Rosario (coord.): Tesouro do léxico patrimonial galego e portugués. Santiago de Compostela: Instituto da Lingua Galega. Dispoñible en: [http://ilg.usc.es/tesouro/gl]. Accedido o: 28 feb. 2021.

WILKINSON, Philip. Le petit Larousse illustré des légendes et mythes. Paris: Larousse, 2016.

Nota do editor:

Artigo submetido para avaliação em: 28 de fevereiro de 2021.

Aprovado em sistema duplo cego em: 06 de maio de 2021. 